\title{
La metáfora como espacio de detenimiento
}

FIGURAS REVISTA ACADÉMICA DE INVESTIGACIÓN

ISSN 2683-2917

Vol. 1, núm. 3, julio-octubre 2020

https://doi.org/10.22201/fesa.figuras.2020.1.3

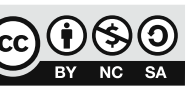

Esta obra está bajo una licencia

Creative Commons Atribución-NoComercial-

Compartirlgual 4.0 Internacional

\section{The metaphor as thoroughness space}

https://doi.org/10.22201/fesa.figuras.2020.1.3.118

\section{(D) Alicia García-Bergua}

El gesto de detenimiento y atención al lenguaje que implica la metáfora es uno de los grandes fundamentos del pensamiento racional. Cuando la metáfora pasa a ser parte del lenguaje escrito, se vuelve objeto de expresión de la imaginación en el lugar preciso de la página, y la mente se reconfigura con ello dando lugar a representaciones, escenarios e imágenes que provienen de las relaciones entre las palabras empleadas.
Con todo esto quiero decir que la palabra escrita crea lo que yo denominaría escenarios mentales y emocionales para pensar, para jugar con las palabras y su significación, para recrear fenómenos con ellas y para plantearse interrogantes. La manera en que la poesía a través de las metáforas se detiene en los hechos o en los pensamientos mismos no difiere en realidad de otros gestos de pensamiento que se llevan a cabo en otras actividades intelectuales. Hay incluso un espíritu de búsqueda que en el caso de los poetas implica una conciencia subjetiva plena y en el caso de los científicos un intento por una total ausencia de ella, que motiva por igual a ambos, poetas y científicos.

Antes de entrar en el tema específico de este ensayo quisiera abordar uno de los estudios científicos más detallados e interesantes que se han hecho del lenguaje humano: el del investigador Terrence W. 
Deacon y que está descrito en su libro Symbolic Species (Especie simbólica). ${ }^{1}$ Lo que lo motivó a hacer este estudio fue la pregunta que le hicieron unos niños sobre si los animales tenían lenguaje en el sentido en que nosotros lo tenemos. Deacon reflexionó sobre el hecho de que el lenguaje no era para nosotros sólo una forma de comunicación, sino una forma de pensar, de representarse simbólicamente los eventos, los objetos y las relaciones con una gran economía referencial. También es una manera de proyectarse en el tiempo y de planear.

\section{Deacon reflexionó sobre el hecho de que el lenguaje no era para nosotros sólo una forma de comunicación, sino una forma de pensar.}

Somos los únicos animales de la Tierra en los que evolucionó esta distintiva manera de tener conciencia. Todo el libro de Deacon trata de cómo se puede haber originado físicamente esto en nuestro cerebro y de qué lo hizo excepcional, aunque siempre pensando que estas excepciones - como nuestra visión por ejemplo y el hecho de que veamos a color - provienen de variaciones genéticas que no se originaron en nosotros como organismos sino en otros, millones de años más antiguos, que no tenían la finalidad que ahora tienen en nosotros.

No voy a entrar aquí en cómo Deacon diferencia, en la primera parte de su libro, las comunicaciones del resto del mundo animal en contraste con el lenguaje humano. Simplemente diré que cita uno de los experimentos más conocidos que se han hecho con delfines

1 Terrence Deacon, The Symbolic Species: The Co-Evolution of Language and the Brain (New York: W. W. Norton, 1997). para comprobar cómo ellos perciben el lenguaje humano sin su gramática, es decir, sin que las palabras cobren una significación según el orden en que se pronuncian. Las perciben simplemente como una señal -hay lenguajes humanos de señales pero abordarlos nos alejaría mucho de nuestro tema principal.

La organización gramatical del lenguaje es lo que le da su poder de representación simbólica y al parecer, según la teoría de Chomsky divulgada por Pinker en su famoso libro El instinto del lenguaje, ${ }^{2}$ esta gramática es un mecanismo innato que trae nuestro cerebro y que se desencadena cuando aprendemos a hablar. Una de las evidencias que señala Pinker de esto es el empeño que tienen los niños pequeños en conjugar regularmente todos los verbos. Actualmente se está tratando de comprobar cómo sucede este desencadenamiento del lenguaje en el cerebro haciendo redes neuronales con inteligencia artificial.

Tanto la ciencia como la poesía son posibles gracias a la mente simbólica que se expresa y manifiesta con el lenguaje, porque con ella se puede describir un universo de fenómenos, objetos y sujetos determinado y además observar, medir y sopesar las relaciones entre ellos. Pero aquí ambas maneras de pensar, las de la poesía y las de la ciencia, se bifurcan pues, como dice Luis Estrada ${ }^{3}$ en un texto que escribió sobre el lenguaje de la ciencia, en la investigación científica el lenguaje se ajusta a los hechos que se van descubriendo. Aquí cabría cierta búsqueda de exactitud similar a la de los poetas para nombrar aquello que

\footnotetext{
2 Steven Pinker, El instinto del lenguaje. Cómo crea el lenguaje la mente (Madrid: Alianza, 1995).

3 Luis Estrada, "La divulgación de la ciencia," Ciencias, no. 27 (1992): 69-76, https://www.revistaciencias. unam.mx/es/175-revistas/revista-ciencias-27/1620-ladivulgaci\%C3\%B3n-de-la-ciencia.html
} 
se va descubriendo. Una vez que se descubren ciertos fenómenos $u$ hechos objetivos, éstos tienen que nombrarse con una precisión unívoca y pone como ejemplos palabras como función endócrina o masa inercial. Al poner estos hechos en una ecuación que mide sus relaciones, combinaciones y proporciones, se pueden reducir a una letra cuyo significado siempre es el mismo, siempre es constante, aunque sea un principio de incertidumbre.

Pero esta manera de representarse o de describir algo no se podría dar sin el gesto que conlleva la metáfora, que en un sentido más actual implica detenerse a pensar en algo concreto utilizando el lenguaje de manera precisa y reflexiva. La metáfora en poesía es un tropo ("tropo" viene de una palabra griega que significa cambio, mudanza) o figura, que consiste en la sustitución de un elemento léxico por otro con el que tiene una o varias semejanzas.

Las metáforas son imágenes mentales; escenarios donde jugamos con elementos reales e imaginarios y establecemos entre ellos relaciones que nos permiten

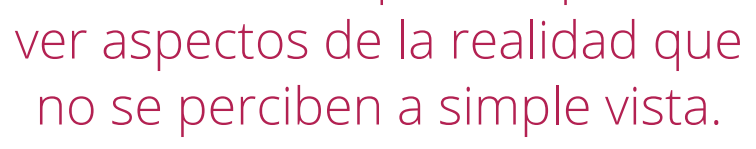

Usamos metáforas todos los días sin darnos cuenta, por ejemplo cuando decimos "El mundo es un pañuelo". A diferencia de la comparación, que en este caso sería "El mundo parece un pañuelo", en la metáfora se realiza un cambio de sentido del término, un cruce imposible entre una realidad y otra. Las utilizamos para detenernos a pensar o a reflexionar muy puntualmente en algo porque las metáforas son, ante todo, imágenes mentales; escenarios donde jugamos con elementos reales e imaginarios y establecemos entre ellos relaciones que nos permiten ver incluso aspectos de la realidad que no se perciben a simple vista.
Creo que este gesto de detenimiento y atención al lenguaje que implica la metáfora es uno de los grandes fundamentos del pensamiento racional. No obstante, según el libro de Walter J. Ong Oralidad y escritura. Tecnologías de la palabra, ${ }^{4}$ publicado en el FCE, que les recomiendo mucho, este detenimiento de la mente para pensar en algo se hizo cada vez más posible con la palabra escrita, y ésta a su vez nos cambió la mente a quienes nos educamos con ella.

En cantos como la Ilíada, ${ }^{5}$ que se transmitieron oralmente, la metáfora era un epíteto intercambiable, un elemento que se variaba para ajustar la métrica de los versos que se improvisaban. En este caso, los epítetos caracterizaban, por ejemplo, a los personajes. La Odisea $^{6}$ en cambio parece más concebida como un texto escrito, que maneja imágenes o escenarios que acuden a nuestra mente; por ejemplo, el momento en que Ulises u Odiseo regresa de incógnito a su casa y derrama una lágrima cuando se encuentra con su perro Argos, que lo reconoce moviendo la cola y muere a sus pies después de esperarlo 20 años. 0 la famosa escena de las sirenas o la de la cueva del Cíclope. Habrá también quienes me dirán aquí que Sócrates no escribió y que Platón al parecer no era tan partidario de la escritura, pero los Diálogos ${ }^{7}$ han llegado a nosotros por escrito.

${ }^{4}$ Walter J. Ong, Oralidad y escritura. Tecnologías de la palabra (México: FCE, 1987).

${ }^{5}$ Homero, Ilíada, intr., vrs. rít. y nts. Rubén Bonifaz Nuño (México: UNAM, 2005, Bibliotheca Scriptorum Graecorum et Romanorum Mexicana).

${ }^{6}$ Homero, Odisea, pról., vrs. rít. e índ. de n. prop. Pedro C. Tapia Zúñiga, est. introd. Albrecht Dihle (México, UNAM, 2014, Bibliotheca Scriptorum Graecorum et Romanorum Mexicana).

7 Platón, Diálogos (Madrid: Gredos, 2006, Biblioteca Clásica). 
Cuando la metáfora pasa a ser parte del lenguaje escrito, se vuelve un objeto de expresión de la imaginación en el lugar preciso de la página y la mente se reconfigura con ello dando lugar a representaciones, escenarios e imágenes que provienen de las relaciones entre las palabras empleadas. No es extraño entonces que el teatro de Shakespeare y del Siglo de Oro estuvieran muy ligados a la poesía: era un teatro cuya escenografía eran las imágenes que los diálogos en verso proyectaban en quienes los escuchaban. Se sabe que en El Globo, por ejemplo, las obras de teatro se representaban casi sin escenografía: el contexto ya venía en lo dicho. Lo mismo debió suceder con las tragedias griegas cuyos textos eran escritos y memorizados. La Divina Comedia, ${ }^{8}$ para muchos el gran antecedente de toda la poesía occidental, es un poema dramático con escenarios conmovedores, aterradores e impresionantes.

Con todo esto quiero decir que la palabra escrita crea lo que yo denominaría escenarios mentales y emocionales para pensar, para jugar con las palabras y su significación, para recrear fenómenos con ellas y para plantearse interrogantes.

En este sentido, creo que la manera en que la poesía, a través de las metáforas, se detiene en los hechos o en los pensamientos mismos, no difiere en realidad de otros gestos de pensamiento que se llevan a cabo en otras actividades intelectuales. Hay incluso un espíritu de búsqueda que en el caso de los poetas implica una conciencia subjetiva plena y en el caso de los científicos un intento por una total ausencia de ella, que motiva por igual a ambos, poetas y científicos.

Esta búsqueda de un sentido o conocimiento interior, que se da en el espacio lingüístico metaforizador

8 Dante Alighieri, Divina Comedia, trad. Luis Martínez de Merlo (Madrid: Cátedra, 1998). de nuestra mente, ha dado lugar a grandes poemas como "Primero sueño" de Sor Juana Inés de la Cruz, ${ }^{9}$ sobre una realidad por la que el alma viaja en sueños sin los sentidos, con el intelecto, según Octavio Paz; ${ }^{10}$ "Muerte sin fin", de José Gorostiza, ${ }^{11}$ que según uno de sus estudiosos, Arturo Cantú, ${ }^{12}$ es el mundo visto como la expresión de un dios totalmente transparente y sin misterio, un dios del que somos el reverso y no tiene en realidad piedad de sus criaturas, un dios que es la muerte; "Piedra de sol" de Octavio Paz, ${ }^{13}$ donde la existencia personal cobra una dimensión espiritual cósmica; "Cantata a solas" de Tomás Segovia, ${ }^{14}$ sobre el encuentro con los otros y la comunidad a través de la poesía, o "Incurable" de David Huerta, ${ }^{15}$ un poema novelado donde se describe un viaje por el infierno de la mente. Todos estos poemas abren un escenario de significación donde las palabras son el vehículo y a la vez el destino de una búsqueda o de un desciframiento. Abren y cultivan a la vez con el lenguaje un pensamiento que se hace real por sus metáforas y que sería lo equivalente a la formulación de un objeto matemático singular por la manera convencional en que se establecen las relaciones significativas entre las palabras.

9 Sor Juana Inés de la Cruz, Obras completas, I. Lírica personal (México: FCE, 1951).

${ }^{10}$ Octavio Paz, Sor Juana Inés de la Cruz o las trampas de la fe (México: FCE, 1982).

${ }^{11}$ José Gorostiza, Poesía (México: FCE, 1971).

${ }^{12}$ Arturo Cantú, En la red de cristal. Edición y estudio de Muerte sin fin de José Gorostiza (México: Universidad Autónoma Metropolitana, 2005).

${ }^{13}$ Octavio Paz, Piedra de sol (México: Tezontle, 1957).

${ }^{14}$ Tomás Segovia, Antología de poesía amorosa (México: UNAM, 2015).

${ }^{15}$ David Huerta, Incurable (Ciudad de México: Ediciones Era, 1987). 
En el caso de la metáfora poética se puede ejercer con ella una plenitud de conciencia, en el sentido de llevar a cabo todos los procesos mentales que la conciencia implica: atención, sensación, percepción, emoción, voluntad, pensamiento, ensoñación, imaginación y recuerdo. Y es una expresión en la que las palabras se abren en su significación, contrario a lo que sucede con los términos en una formulación científica ya sea matemática o descriptiva.

Las metáforas nos permiten ver cosas de la realidad que no se perciben a simple vista. Un ejemplo de ello es este poema del poeta catalán Joan Vinyoli (1914$1984)^{16}$ que retrata muy bien metafóricamente la atmósfera de la posguerra en España.

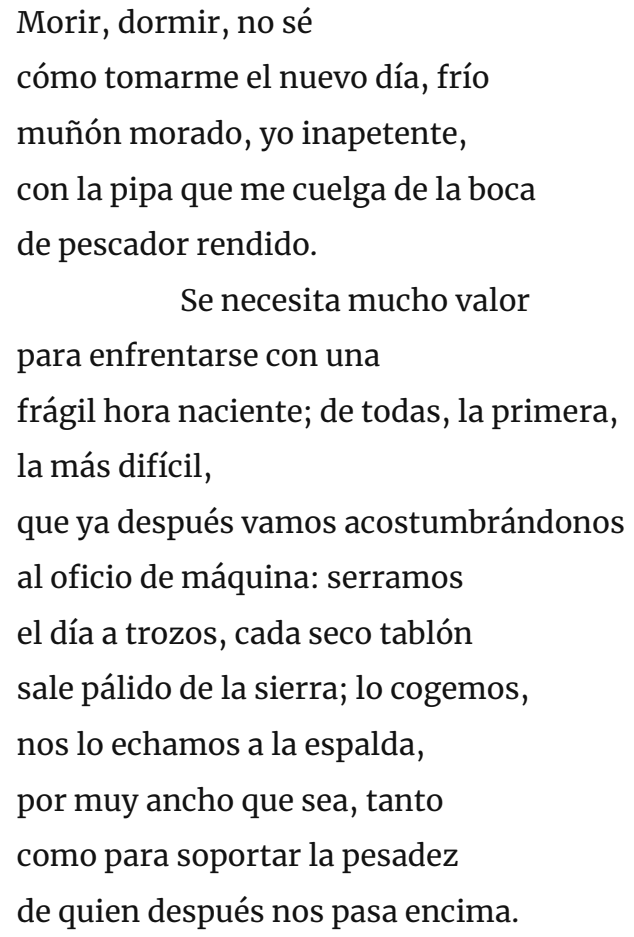

${ }^{16}$ Joan Vinyoli, "Madrugada morada con fábricas." La mano en el fuego (Barcelona: Editorial CandayaInstitut Ramion Llull Lengua y Cultura Catalanas, 2014).
En este poema el pensamiento metafísico cobra una tesitura completamente física, no es un universo conceptual abstracto. Es una imagen que empieza siendo muy real: la de un obrero que se despierta con frío, sin hambre y dudando de estar vivo o muerto con la pipa de pescador colgando de la boca. Y la manera de lidiar con ese tiempo humano en el poema no es pensando en él, sino tratándolo como un tablón de madera que ayuda a defenderse de la muerte y a soportar el peso de los muertos y de los vivos. Que el tiempo de la vida diaria sea un tablón implica que en él se puede navegar, también por supuesto naufragar y ser enterrado.

\section{Hay metáforas que condensan la materialización de una sensación y un pensamiento.}

La atmósfera del poema, morada, fría y fabril, me parece un escenario de una obra de Samuel Beckett, pues con implementos y rasgos mínimos retrata no sólo un personaje, sino toda una situación existencial que nos embarga y ensombrece. El poema tiene una atmósfera de posguerra en la que las personas comunes han quedado en un estado de máxima vulnerabilidad e indefensión, pero también con lo esencial que es su tiempo de vida diaria, y tienen que trabajarlo, aserrarlo para quitarle las asperezas y darle la forma de sostén y mínima salvación. Además ese tiempo se limita en el poema a ese día en que el personaje despierta, no hay pasado ni futuro, no hay ventana ni puerta que lleven más allá. Es el tiempo del hombre moderno, encerrado en su día, tratando de construirse de la mañana a la noche como si la vida fuera un trabajo más, sin ocio, sin resquicios por los que escaparse.

En metáforas como las de este poema, se hace un efecto de condensación; probablemente hubo muchas 
mañanas así para el poeta que se volvieron esta materialización de una sensación y un pensamiento.

En el poema de Xavier Villaurrutia "Cementerio en la nieve", ${ }^{17}$ al otorgarle a la nieve que cae el significado de la muerte humana, se inaugura un escenario más allá del cementerio mismo: el de la redundancia y la infinitud con la que el poeta imagina la muerte. En el poema se define la muerte como algo que se dobla o se cierra sobre sí mismo al infinito, convirtiéndose en una nada persistente y evidente que se define como las insensibles piedras de nieve sobre las tumbas, la nieve sobre la nieve, lo blanco sobre lo blanco, el sueño sin sueños, los ojos en blanco, la caída de un silencio sobre otro, las losas exangües, los labios que se cierran, los pájaros que pasan de largo, la mano eternamente posada sobre sí misma. Se define aquí la muerte como una eterna redundancia que sería la nada para este autor.

\section{"Cementerio en la nieve"}

A nada puede compararse un cementerio en la nieve, ¿Qué nombre dar a la blancura sobre lo blanco? El cielo ha dejado caer insensibles piedras de nieve sobre las tumbas, y ya no queda sino la nieve sobre la nieve como la mano sobre sí misma eternamente posada.

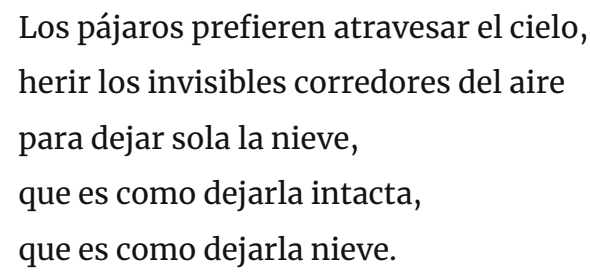

${ }^{17}$ Xavier Villaurrutia, Obras: Poesía, teatro, prosas varias, críticas (México: FCE, 1953).
Porque no basta decir que un cementerio en la

nieve

es como un sueño sin sueños

ni como unos ojos en blanco.

Si algo tiene de un cuerpo insensible y dormido, de la caída de un silencio sobre otro y de la blanca persistencia del olvido, ja nada puede compararse un cementerio en la nieve!

Porque la nieve es sobre todo silenciosa, más silenciosa aún sobre las losas exangües: labios que ya no pueden decir una palabra.

En el poema de Alfonso Reyes "La canción de mis ventanas" 18 vemos cómo la luz de la ventana cobra muchas dimensiones. Es un poema que en realidad habla de la necesidad de cultivar la inteligencia en un mundo oscuro y lleno de caos. En la primera estrofa ("Luz de mis ventanas que, a la calle oscura, / sales publicando mi oculta ventura: / luz hospitalaria, faro que me guía: / afuera es la noche, adentro es el día.") el poeta define la luz de su ventana como un faro que lo guía en la oscuridad del mundo exterior. Es la luz de las lámparas que iluminan su vida cotidiana y sus lecturas. Hay entonces en este poema una curiosa inversión donde la luz del entendimiento que es producto del reposo, la serenidad y la calma hogareña, es la que verdaderamente ilumina la vida. Hay que añadir aquí que escribió este poema en España entre 1914 y 1915, habiendo vivido recientemente en la Ciudad de México no sólo la muerte de su padre, el general Bernardo Reyes en la terrible Decena Trágica. Poder estar en su casa en Madrid disfrutando de recogimiento y paz le suscitó este poema que convierte la vida interior e intelectual en algo luminoso, en

\footnotetext{
${ }^{18}$ Alfonso Reyes, Poesía (México: FCE, 2018).
} 
contraste con lo oscuro de los acontecimientos sociales del momento.

La ventana es a su vez aquí la frontera entre el universo interior del intelecto luminoso del poeta y el mundo exterior, y desde ella lo que sucede afuera se puede escuchar como arrullo y canción -es decir, como parte de la creación poética- como lo podemos ver en la estrofa: "Voces de la calle, lejano revuelo / de pasos y charlas, arrullo y canción... / Desde mi ventana, mi trozo de cielo / ostenta, temblando, los ojos de Orión". Al final de esta estrofa se menciona que desde la ventana puede verse la constelación de Orión, que simboliza al temible cazador de la mitología griega y, al mismo tiempo, los ojos protectores de Orus en la mitología egipcia. Es una ventana desde la cual el intelecto puede ver el cosmos sintiéndose protegido.

En la siguiente estrofa ("Lejos se retuerce la eterna quimera, / por donde comienza la turbia ciudad. / Una paz balsámica me llega de afuera, / y adentro del alma navega Simbad.") se insiste en la lejanía de la ciudad turbulenta y en la paz que implica esta luz interior que permite navegar interiormente como Simbad, es decir, ese personaje de varias mitologías que fue inicialmente un marinero náufrago, también egipcio.

La siguiente estrofa ("O bien, por las tardes, al Héspero claro / y a la rutilante hora del pastor, / icon qué intenso júbilo saludo mi faro! // La reverberante lumbre de mi faro / abre el abanico de su resplandor."), ya hace alusión a la ventana claramente como un faro y dice que a la hora en que aparece el planeta Venus como lucero vespertino -o sea, no como Afrodita que es como lucero del alba-, y a la hora en que regresan los pastores, se siente atraído por ese faro que no sólo es luz sino que tiene lumbre, es decir, calor de hogar que resplandece a su regreso.
En las dos siguientes estrofas ("Ventana, refugio, mirador del mundo / desde donde oteo las calles de sol, / desde donde asomo yo, meditabundo, / cautelosos palpos como un caracol. // Desde donde escucho lo que dice el viento / y ausculto la noche como un corazón: / imagen confusa de mi pensamiento / que es una perenne interrogación.") el significado de la ventana se ha ampliado mucho, es refugio, mirador del mundo y concha protectora; es el lugar desde el cual él se asoma y medita sopesando sus reflexiones cuidadosamente como un caracol desde su concha. La ventana, pues, es una gran imagen metafórica, que en este poema adquiere gran cantidad de sentidos, connotaciones y reverberaciones.

En las siguientes dos estrofas ("Cuando, con los años, próspera la casa / de la inquieta prole se alegre al rumor, / tenderé las manos al tiempo que pasa, / pediréa los cielos todo su esplendor, // haré que se enciendan todos mis hachones, / soltaré la fiesta de mi corazón. / Dos caudas de palmas, como bendiciones, / cruzaré en las rejas del alto balcón.") la ventana se convertirá también en una manera de abrazar el tiempo que pasa como la promesa de alumbramiento y de felicidad, y entonces se convertirá en un balcón, es decir, será una ventana que sobresalirá y le permitirá cruzar sobre sus rejas dos caudas de palmas como bendiciones, igual que las palmas con las que recibieron a Jesús en Jerusalén, que son las palmas que se bendicen en el Domingo de Ramos y que a su vez proclaman el reinado de Jesús en el corazón, por eso dice en la misma estrofa que soltará la fiesta de su corazón.

"La canción de mis ventanas"

Luz de mis ventanas que, a la calle oscura, sales publicando mi oculta ventura: luz hospitalaria, faro que me guía: afuera es la noche, adentro es el día. 
Voces de la calle, lejano revuelo

de pasos y charlas, arrullo y canción...

Desde mi ventana, mi trozo de cielo

ostenta, temblando, los ojos de Orión.

Lejos se retuerce la eterna quimera, por donde comienza la turbia ciudad.

Una paz balsámica me llega de afuera, y adentro del alma navega Simbad.

O bien, por las tardes, al Héspero claro y a la rutilante hora del pastor, ¡con qué intenso júbilo saludo mi faro!

La reverberante lumbre de mi faro abre el abanico de su resplandor.

Ventana, refugio, mirador del mundo desde donde oteo las calles de sol, desde donde asomo yo, meditabundo, cautelosos palpos como un caracol.

Desde donde escucho lo que dice el viento y ausculto la noche como un corazón: imagen confusa de mi pensamiento que es una perenne interrogación.

Cuando, con los años, próspera la casa de la inquieta prole se alegre al rumor, tenderé las manos al tiempo que pasa, pediré a los cielos todo su esplendor,

haré que se enciendan todos mis hachones, soltaré la fiesta de mi corazón.

Dos caudas de palmas, como bendiciones, cruzaré en las rejas del alto balcón.

\section{Referencias}

Alighieri, Dante. Divina Comedia. Traducción de Luis Martínez de Merlo. Madrid: Cátedra, 1998.

Cantú, Arturo. En la red de cristal. Edición y estudio de Muerte sin fin de José Gorostiza. México: Universidad Autónoma Metropolitana, 2005.

Cruz, Sor Juana Inés de la. Obras completas, I. Lírica personal. México: FCE, 1951.

Deacon, Terrence W. The Symbolic Species: The Co-Evolution of Language and the Brain. New York: W.W. Norton, 1997.

Estrada, Luis. "La divulgación de la ciencia." Ciencias, no. 27 (1992): 69-76, https://www.revistaciencias.unam.

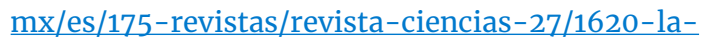
divulgaci\%C3\%B3n-de-la-ciencia.html Revisado el 11 de mayo, 2020.

Gorostiza, José. Poesía. México: FCE, 1971.

Homero. Ilíada. Introducción, versión rítmica y notas de Rubén Bonifaz Nuño. México: UNAM, 2005 (Bibliotheca Scriptorum Graecorum et Romanorum Mexicana).

Homero. Odisea. Prólogo, versión rítmica e índice de nombres propios de Pedro C. Tapia Zúñiga, estudio introductorio de Albrecht Dihle. México: UNAM, 2014, (Bibliotheca Scriptorum Graecorum et Romanorum Mexicana).

Huerta, David. Incurable. México: Ediciones Era, 1987.

Ong, Walter J. Oralidad y escritura. Tecnologías de la palabra. México: FCE, 1987.

Paz, Octavio. Piedra de sol. México: Tezontle, 1957.

_. Sor Juana Inés de la Cruz o las trampas de la fe. México: FCE, 1982.

Pinker, Steven. El instinto del lenguaje. Cómo crea el lenguaje la mente. Madrid: Alianza, 1995.

Platón. Diálogos. 9 vols. Madrid: Biblioteca Clásica Gredos, 2006.

Reyes, Alfonso. Poesía. México: FCE, 2018.

Segovia, Tomás. Antología de poesía amorosa. México: UNAM, 2015.

Villaurrutia, Xavier. Obras: Poesía, teatro, prosas varias, críticas. México: FCE, 1953.

Vinyoli, Joan. La mano en el fuego. Edición y prólogo de Jordi Llavina, traducción de Carlos Vitale. Barcelona: Editorial Candaya-Institut Ramion Llull Lengua y Cultura Catalanas, 2014.

AlFonso Reyes 